drawing ocean bottom water downwards into the oceanic crust, but at a slower rate $-1,500 \mathrm{I} \mathrm{h}^{-1}$ compared with $6,0001 \mathrm{~h}^{-1}$. In the two year period, $50 \times 10^{6} \mathrm{~kg}$ of sea water have been drawn into the crust.

An apparent discrepancy between the Leg 83 findings and the ophiolite model did turn up, however. According to the literature ophiolite rocks appear to have generally re-equilibrated under increasing temperature metamorphic facies, Leg 83 basalts display only partial recrystallization, showing they have not reached equilibrium. Also Leg 83 rocks do not grade with increasing depth into increasingly higher-temperature facies. Some of the minerals of lowesttemperature alteration and the least altered rocks were found in the middle cores of the dikes complex.

The sequence of alteration has not yet been resolved by analysis on board the Challenger. Recovered rocks show the effects of at least two stages of alteration: a greenschist facies (hotter) event depositing actinolite, chlorite and epidote into veins and actinolite, chlorite, sphene and albite throughout the rock matrix, and a zeolite facies (lower temperature) event, characterized by laumontite, epidote, chlorite and smectite. Anhydrite seems to

occur with both facies mineral pargenesis in veins and appears to be a late forming mineral. It is not clear whether the stockwork metallogenesis belongs with the hotter or the cooler event. The question still unresolved is whether both events took place at the ridge axis or whether the cooler event is occurring now on the flank of the ridge. Significantly, water in formation pores has the composition predicted to be in equilibrium with currently occurring alteration in the rock. Formation waters therefore do not reflect the greenschist facies (hot) type of event.

This is an important geophysical issue as well, for the plumbing system of the dikes and lower pillows is clearly plugged up by alteration, whereas the top of the crust (layer 2A) is obviously open to aquifer-type flow. Closer to the ridge, was layer $2 \mathrm{~A}$ thicker and convection more pervasive? Or has convection - even at the ridge axis always been limited to the upper $500 \mathrm{~m}$ of the oceanic crust now at Hole 504B?

Shore-based analysis of Leg 83 results promises much excitement. In any event, the myth of not being able to drill deep in the oceanic crust has been proved to be just that. Leg 83 left Hole 504B clean and ready for even deeper drilling on a possible future leg - layer 3 or bust!

\title{
Ocean floor conductivity measured
}

\section{from T.J.G. Francis}

A WIDE range of electrical methods has been used for several decades over land to measure the conductivity of the underlying rocks. But whereas the study of the electrical properties of rocks has become the most important method of geophysical exploration for metal ore bodies, the application of these techniques to the sea bed, even in the shallow waters of continental shelves, has been severely restricted by the high conductivity of seawater. Much effort has been directed to getting round this difficulty and in Geophysical Research Letters, P.D. Young and C.S. Cox have now described an active-source electromagnetic sounding experiment carried out on the ocean floor ${ }^{1}$. The technique offers new possibilities for studying the geology of the oceanic crust.

Magnetotelluric sounding, in which the horizontal magnetic and electric fields of naturally occurring electromagnetic signals are observed, has been carried out on the ocean floor since 1965 (ref.2). The conductivity of the ocean eliminates frequencies above about 10 c.p.h. $(0.003$ $\mathrm{Hz}$ ) however, so that the method is suitable only for studying the conductivity of the mantle on a scale of hundreds of kilometres

T.J.G. Francis is Head of Geophysics at the Institute of Oceanographic Sciences, Wormley, Godalming, Surrey GU8 SUB. and is thus insensitive to the conductivity structure of the crust and uppermost mantle. Using an array towed at the sea surface behind a ship to measure the resistivity of the sea bed on the continental shelf ${ }^{3}$, it has been possible to distinguish between unconsolidated sediments and hard rock and to detect the presence of a sulphide ore body, but this method is not thought practicable in oceanic depths.

In the novel active-source electromagnetic sounding experiment of Young and $\mathrm{Cox}^{1}$, low-frequency signals of $0.25-2.25 \mathrm{~Hz}$ were detected at a range of 19 $\mathrm{km}$ close to the axis of the East Pacific Rise at $21^{\circ} \mathrm{N}$. The transmitting antenna, lowered from a ship, consisted of an $800 \mathrm{~m}$ long insulated wire through the ends of which $70 \mathrm{~A}$ peak alternating current was passed into the sea. The freely deployed receiver measured the electric field at two 9 $m$ long crossed antennas and at the end of the experiment floated back to the surface for recovery. The observations have been modelled to yield a conductivity structure of the crust and upper mantle to a depth of $30 \mathrm{~km}$ beneath the sea floor.

The important thing about the work of Young and Cox is not so much their results, fascinating though they are, as the potential which the technique may have for future studies of the geology of the ocean floor. Our present knowledge of the deeper geological structure of the ocean crust has been obtained largely by seismic methods. Reflection methods have told us most about the structure of the sedimentary layers and refraction about the underlying basement. However, the translation of velocity structures into geology is ambiguous and compressional wave velocities are insensitive to many of the properties of the ocean crust which now interest earth scientists. By contrast, the electrical conductivity of a rock is extremely sensitive to the presence of cracks filled with seawater, to even smaller amounts of partial melting and to the presence of sulphide ore minerals. All have the capacity to increase the conductivity of a rock by two or more orders of magnitude.

The extent to which seawater penetrates newly formed oceanic crust has been a subject of considerable interest ever since it was first demonstrated by Lister a decade $\mathrm{ago}^{4}$. Now Young and Cox have demonstrated that close to the East Pacific Rise, the high-conductivity $\left(0.1 \mathrm{~S} \mathrm{~m}^{-1}\right)$ basalts penetrated with seawater are no more than $1.4 \mathrm{~km}$ thick. This result has already received support from large-scale resistivity measurements made on Leg 83 of the Deep-Sea Drilling Project in Hole 504B on the Costa Rica Rift ${ }^{5}$ (see previous article). Seawater may penetrate much more deeply into the crust of slowly spreading ridges and active-source electromagnetic sounding is probably the best method for measuring it.

This technique may also provide the means of finding magma chambers beneath the axes of mid-oceanic ridges. The existence of such magma chambers has long been postulated, but finding them has proved difficult, particularly on slowly spreading ridges where seismic refraction experiments have produced negative results ${ }^{6}$.

Finally, sulphide ore bodies are now thought to exist in the upper levels of the oceanic crust at a frequency of one ore body of horizontal area $0.1 \mathrm{~km}^{2}$ per $20 \mathrm{~km}^{2}$ (ref.7). Attempting to find such ore bodies by drilling would be futile, since on the average it would take 200 holes to discover one ore body. Deep penetration logging of the bore holes could improve these odds, but only by a factor of about four. Activesource electromagnetic sounding is certainly the best available means of finding such bodies once they have become buried by pillow lavas and sediment.

Thus Young and Cox have demonstrated a technique which, if widely deployed, possibly using other frequencies and source-receiver configurations, could provide answers to many of the problems which have eluded solution by more conventional marine geophysical techniques. $\square$

\footnotetext{
Young, P.D. \& Cox, C.S. Geophys. Res. Lett. 8, 1043 (1981).

. Filloux, J.H. Nature 269, 297 (1977)

Francis, T.J.G. Rep. Inst. geol. Sci. No. 77/4 (1977) Lister, C.R.B. Geophys. J.R. astr. Soc. 26, 515 (1972). Becker, K. Personal communication (1982).

Fowler, C.M.R. Geophys. J.R. astr. Soc. 47, 459 (1976) Cann, J.R. J. geot. Soc. Lond. 137, 381 (1980).
} 